\title{
6 SPINAL INJURY IN SPORTS
}

R C Mishra Senior consultant, Apollo Hospital, Ranchi, Jharkhand, India

10.1136/bjsm.2010.078725.6

Nowadays, the scene of sports has changed as it involves not only money but prestige for self and country. Hence, sports has become aggressive. Any sport which involves movement and momentum can cause spinal injury, like football, water sports, wrestling, rugby, transpoling and ice hockey.

Spinal injury can be simple to serious leading to paralysis or death.

The team physician should:

1. Identify the injury

2. Stabilise the athlete

3. Transport the athlete to a proper centre.

Above all, the team physician should be able to explain the prevention of spinal injury. 